\title{
A Pilot Survey of the CurRent Scope of Practice of SOUTH AFRICAN PHYSIOTHERAPISTS IN INTENSIVE CARE UNITS
}

\begin{abstract}
Objective: A pilot study was conducted to determine the current scope of practice of South African physiotherapists working in intensive care units in the government and the private sectors. These findings were compared to the findings from a European survey with regard to the role of the physiotherapist in European intensive care units.

Methodology: Ninety questionnaires were distributed nationwide to secondary and tertiary government hospitals as well as to private practitioners involved in cardiopulmonary physiotherapy. The private practitioners included in this

\section{Van Asw egen $\mathrm{H}$, MSc Physiotherapy; Potterton J, M Sc Physiotherapy ${ }^{1}$}

${ }^{1}$ Lecturer, Physiotherapy Department, University of the Witwatersrand. survey were listed in the Private Practitioners Association Official Members Directory. Junior and senior physiotherapists working in the intensive care units of their respective hospitals participated in completing the questionnaire. Comparisons between government and private sector data and between the South African survey and the European survey were carried out using the $\chi^{2}$ test for non-parametric data. A p-value of less than 0.05 was considered to be statistically significant.

Results: Fifty-four questionnaires were analyzed and represented $60 \%$ of questionnaires sent out. Respondents to the South African survey reported 28\% percent of all ICUs had between 9 - 12 beds; 83\% physiotherapists indicated the availability of an on-call service during the night and $96 \%$ physiotherapists had a weekend physiotherapy service. Ninety-two percent of physiotherapists working in the government sector supervised students compared to $44 \%$ of physiotherapists in the private sector. Between $9 \%$ and $27 \%$ of physiotherapists in government and private hospitals actively participated in research in ICU. There were no statistically significant differences in the use of respiratory physiotherapy, mobilization and positioning between respondents to the European survey and those of the South African survey respectively.

Conclusion: The response rate to this questionnaire was good. It was evident from this pilot survey that the scope of practice of physiotherapy in ICU didn't differ significantly between the government and private sector in South Africa. The role of the intensive care physiotherapist in South Africa was similar to that of the European physiotherapist working in ICU.
\end{abstract}

KEY WORDS: SCOPE OF PHYSIOTHERAPY PRACTICE, INTENSIVE CARE UNIT, GOVERNMENT SECTOR, PRIVATE SECTOR.

\section{INTRODUCTION}

Patients that are admitted to the Intensive Care Unit (ICU) need intensive monitoring, support and therapy to help them recover from their critical illness (Hough, 2001). Physiotherapy is an integral part of the multidisciplinary management of the critically ill patient in most developed countries. The role that physiotherapists play in the ICU differs considerably depending on the country in which the ICU is located, staffing levels, training, expertise and the referral method between the intensivist/ physician and the physiotherapist (Stiller 2000). Physiotherapists are routinely involved in ICU patient care especially regarding respiratory care and limb mobilization (Norrenberg and Vincent 2000). Norrenberg and Vincent (2000) tried to establish a profile of European physiotherapists working in intensive care units through the use of postal questionnaires. Their response rate was $22 \%$ (29/60 questionnaires returned by units in the United Kingdom and 4/22 questionnaires returned by units from Sweden), which is low. Their low response might be attributed to them sending the questionnaires through the senior intensive care unit physicians instead of to physiotherapists directly. The active professional role of physiotherapists varied between countries. These roles included mobilization, positioning, respiratory therapy, airway suction, and implementation and supervision of non-invasive positive pressure ventilation. In their study, Norrenberg and Vincent (2000) found that only $25 \%$ of respondents reported that physiotherapists were responsible for extubating patients in ICU (mainly in Belgium and the United Kingdom) while 13\% of respondents stated that physiotherapists were involved in adjusting mechanical

\section{CORRESPONDENCE TO:}

Heleen van Aswegen

Physiotherapy Department

University of the Witwatersrand

Johannesburg

Tel: (011) 717-3702

Fax:(011) 717-3719

E-mail: vanaswegenh@therapy.wits.ac.za 
ventilation (mainly in Belgium). Norrenberg and Vincent's (2000) study cannot provide a true profile of the role of European physiotherapists in intensive care units due to the small response rate. The authors did not state whether their questionnaire was tested for reliability or validity.

The researchers could not find any literature on the scope of practice of the South African physiotherapist in the intensive care unit. Clinical physiotherapy practice may differ significantly between countries and between the government and private sectors in South Africa. Therefore, the researchers conducted this pilot survey to determine the current scope of practice of the South African physiotherapist working in ICU (government and private sectors) to create a foundation for future research into this field. The researchers compared their findings with those of the European survey to determine a comparison of scope of practice between South Africa and international countries.

\section{METHOD}

The questionnaire devised by Norrenberg and Vincent (2000) was adapted for use in this survey. All questions which related exclusively to European working conditions and all clinical questions were excluded. Questions, included in this pilot survey, were asked about the demographics of the respondents' intensive care units and the respondents' professional role in the ICU (questionnaire available on request from the Editor).

Questionnaires were distributed randomly to the heads of physiotherapy departments in known secondary and tertiary government hospitals nationwide through South Africa. Questionnaires were also distributed to private practitioners, working in the cardiopulmonary field, listed in the South African Society of Physiotherapy Private Practitioners Association Official Membership Directory. A letter, which outlined the full purpose of the survey, was included with the questionnaire. This letter also explained that participation in this survey was voluntary and failure to return the questionnaire would be regarded as non-participation in this survey. All questionnaires were treated as anonymous as no details regarding the names of the correspondents or of the hospitals where correspondents worked were asked. Questionnaires were sent out in August 2003 and respondents were given 3 months to complete the ques-

Table 1: Demographics of respondents' hospitals in South African survey.

\begin{tabular}{|c|c|c|c|c|c|}
\hline \multicolumn{2}{|c|}{ HOSPITAL } & \multicolumn{2}{|c|}{ INTENSIVE CARE UNITS } & \multicolumn{2}{|c|}{ SIZE OF INTENSIVE CARE UNITS } \\
\hline Classification & $\begin{array}{l}\text { Percentage of } \\
\text { respondents }\end{array}$ & Classification & $\begin{array}{l}\text { Percentage of } \\
\text { respondents }\end{array}$ & $\begin{array}{c}\text { Number of } \\
\text { beds }\end{array}$ & $\begin{array}{l}\text { Percentage of } \\
\text { respondents }\end{array}$ \\
\hline $\begin{array}{l}\text { University- } \\
\text { affiliated } \\
\text { private hospital } \\
(\mathrm{n}=4)\end{array}$ & $7 \%$ & Mixed ICU & $72 \%$ & $<6$ & $11 \%$ \\
\hline $\begin{array}{l}\text { Private hospital } \\
\qquad(n=33)\end{array}$ & $61 \%$ & Surgical ICU & $4 \%$ & $6-8$ & $26 \%$ \\
\hline $\begin{array}{l}\text { University- } \\
\text { affilia ted } \\
\text { government } \\
\text { hospitals } \\
(\mathrm{n}=11)\end{array}$ & $20 \%$ & Medical ICU & $2 \%$ & $9-12$ & $28 \%$ \\
\hline \multirow[t]{4}{*}{$\begin{array}{c}\text { Government } \\
\text { hospitals } \\
(n=6)\end{array}$} & $11 \%$ & $\begin{array}{l}\text { Medico- } \\
\text { surgical ICU }\end{array}$ & $6 \%$ & $13-18$ & $17 \%$ \\
\hline & & N eurosurgical ICU & $2 \%$ & $>18$ & $19 \%$ \\
\hline & & Cardiothoracic ICU & $15 \%$ & & \\
\hline & & Paediatric ICU & $26 \%$ & & \\
\hline
\end{tabular}

Table 2: Training and educational profiles of respondents in South African survey.

\begin{tabular}{|l|c|c|c|c|}
\hline & Government & $\begin{array}{c}\text { University-affiliated } \\
\text { government }\end{array}$ & Private & $\begin{array}{c}\text { University-affiliated } \\
\text { private }\end{array}$ \\
\hline $\begin{array}{l}\text { Postgraduate } \\
\text { qualification in ICU }\end{array}$ & $0 \%$ & $9 \%$ & $36 \%$ & $25 \%$ \\
\hline Research participation & $17 \%$ & $27 \%$ & $9 \%$ & $25 \%$ \\
\hline Seminars & $17 \%$ & $64 \%$ & $49 \%$ & $50 \%$ \\
\hline Student training & $83 \%$ & $100 \%$ & $12 \%$ & $75 \%$ \\
\hline
\end{tabular}


tionnaire and send it back to the researchers in the self-addressed envelope provided. Junior and senior physiotherapists participated in completing the questionnaires.

Comparisons between government and private sector data and between the South African survey and the European survey were carried out using the $\chi^{2}$ test for non-parametric data. A p-value of less than 0.05 was considered to be statistically significant.

\section{RESULTS}

A total of 90 questionnaires were sent out and 54 questionnaires were returned (60\% of questionnaires) by November 2003 (see Table 1). Fifty percent of respondents from the government sector and $50 \%$ of respondents from the university-affiliated private sector reported
3 - 4 full-time physiotherapists that worked in their intensive care units. Forty-five percent of the respondents from the university-affiliated government sector reported more than four full-time physiotherapists that worked in their intensive care units. The reported availability of senior physiotherapists working permanently in the ICU was as follows: two of the six respondents from the government sector (34\%), eight of the 11 respondents from the universityaffiliated government sector (73\%), three of the four respondents from the university-affiliated private sector $(75 \%)$ and 28 of the 33 respondents from the private sector $(85 \%)$. Fifty percent of the government sector and universityaffiliated private sector respondents indicated that they have an on-call service available for their ICUs during

Table 3: Percentage of respondents in South African survey that use specific physiotherapy techniques in ICU, categorized by hospital sector.

\begin{tabular}{|l|c|c|c|c|c|}
\hline \multirow{2}{*}{$\begin{array}{l}\text { Physiotherapy } \\
\text { Techniques }\end{array}$} & \multicolumn{2}{|c|}{ Government } & \multicolumn{2}{c|}{ Private } & P-value \\
\cline { 2 - 6 } & Yes & No & Yes & No & \\
\hline Man Tech & $100 \%$ & $0 \%$ & $100 \%$ & $0 \%$ & N/A \\
\hline PD & $82 \%$ & $18 \%$ & $92 \%$ & $8 \%$ & 0.1 \\
\hline Suction & $100 \%$ & $0 \%$ & $98 \%$ & $2 \%$ & N/A \\
\hline Intub & $0 \%$ & $100 \%$ & $1 \%$ & $99 \%$ & N/A \\
\hline Extub & $65 \%$ & $35 \%$ & $65 \%$ & $35 \%$ & N/A \\
\hline M ob & $100 \%$ & $0 \%$ & $95 \%$ & $5 \%$ & N/A \\
\hline Position & $94 \%$ & $6 \%$ & $92 \%$ & $8 \%$ & N/A \\
\hline IS & $41 \%$ & $59 \%$ & $59 \%$ & $41 \%$ & 0.1 \\
\hline IPPB & $29 \%$ & $71 \%$ & $73 \%$ & $27 \%$ & 0.0005 \\
\hline M HI & $82 \%$ & $18 \%$ & $57 \%$ & $43 \%$ & 0.1 \\
\hline W eaning & $12 \%$ & $88 \%$ & $22 \%$ & $78 \%$ & 0.1 \\
\hline A djust MV & $12 \%$ & $88 \%$ & $16 \%$ & $84 \%$ & $\mathbf{0 . 1}$ \\
\hline N IPPV & $18 \%$ & $82 \%$ & $32 \%$ & $68 \%$ & $\mathbf{0 . 1}$ \\
\hline Blow-bottle & $71 \%$ & $29 \%$ & $68 \%$ & $32 \%$ & $\mathbf{0 . 1}$ \\
\hline
\end{tabular}

Man Tech = manual techniques

Intub = intubation;

Mob = mobilization

IS = incentive spirometry

$\mathrm{N} / \mathrm{A}=$ not applicable

$\mathrm{NIPPV}=$ non-invasive positive pressure ventilation

IPPB = intermittent positive pressure breathing the night. Respondents from the university-affiliated government sector and the private sector indicated the availability of such a service as $82 \%$ and $94 \%$ respectively. Ninety-six percent of respondents (overall) indicated the availability of a weekend duty service to their intensive care units.

The training and educational profile of respondents working in ICU in each sector in South Africa is reflected in Table 2. The physiotherapists working in the university-affiliated government sector indicated the highest rates of physiotherapy student supervision, participation in hospital seminars and participation in clinical research.

Table 3 shows the respondents' responses regarding the scope of physiotherapy practice in South Africa. There were no statistically significant differences between physiotherapy techniques used in the government sector compared to the private sector except for the use of intermittent positive pressure breathing (IPPB). Almost $100 \%$ of the respondents in the government and private sectors used manual therapy techniques, suction, mobilization and positioning in the ICU. Very little physiotherapy involvement (in both sectors) was indicated during adjustment of mechanical ventilation, weaning from mechanical ventilation or in the implementation and supervision of noninvasive positive pressure ventilation (NIPPV). Only $1 \%$ of the respondents from the private sector indicated involvement with endotracheal intubation.

The comparison between scopes of physiotherapy practices in intensive care units in the South African survey with that of the European survey is represented in Table 4. From the information in this table it is clear that the majority of the physiotherapists, who responded to the South African survey, and those who responded to the European survey, practiced respiratory physiotherapy, mobilization and positioning. Ninetyeight percent of South African respondents were involved with suctioning and $65 \%$ were involved with extubation compared to $70 \%$ and $25 \%$ of European respondents respectively. European respondents were more involved with the implementation and supervision of NIPPV. The differences in practice regarding suctioning, extubation and 
administration of NIPPV were statistically significant $(p<0.05)$ between the results of the South African survey and that of the European survey. A small percentage of respondents in the European and South African surveys were involved in endotracheal intubation, adjustment of mechanical ventilation and weaning protocols to terminate mechanical ventilation as reflected in Table 4.

\section{DISCUSSION}

At the time of writing this report there had been no survey conducted in South Africa to establish the current scope of practice of physiotherapists in intensive care units. This pilot survey provided data towards the establishment of the scope of practice of the physiotherapist working in the intensive care unit in South Africa, both in the government and the private sectors. The South African survey results were compared with those of a European survey published by Norrenberg and Vincent in 2000. The information obtained in this survey was preliminary as the questionnaire used was adapted from the European survey and was not validated. Response rate to the South African survey was good (60\%) but it must be remembered that questionnaire studies always carry an intrinsic selection bias in that only the most motivated bother to answer.

In Norrenberg and Vincent's survey (2000) it was found that $33 \%$ of the respondents reported the availability of a physiotherapist to the ICU at night compared to $42 \%$ availability at the university hospitals. The South African survey results indicated $50 \%$ of the government sector and university-affiliated private sector respondents have an on-call service available for their ICUs during the night. Respondents from the university-affiliated government sector and the private sector indicated the availability of such a service as $82 \%$ and $94 \%$ respectively. Norrenberg and Vincent (2000) reported that the university hospitals in Europe who responded to their survey, had physiotherapists available during the weekend. The South African survey showed $96 \%$ of respondents (overall) have a weekend duty service available to their intensive

Table 4: Comparison of physiotherapy techniques used by respondents working in ICU between the European and South African surveys.

\begin{tabular}{|l|c|c|c|c|c|}
\hline \multirow{2}{*}{$\begin{array}{l}\text { Physiotherapy } \\
\text { Techniques }\end{array}$} & \multicolumn{2}{|c|}{ Europe } & \multicolumn{2}{c|}{ South Africa } & P-value \\
\cline { 2 - 6 } & Yes & No & Yes & No & \\
\hline Resp Tx & $98 \%$ & $2 \%$ & $98 \%$ & $2 \%$ & N/A \\
\hline M ob & $100 \%$ & $0 \%$ & $98 \%$ & $2 \%$ & N/A \\
\hline Position & $90 \%$ & $1 \%$ & $95 \%$ & $5 \%$ & $\mathbf{0 . 1}$ \\
\hline Suction & $70 \%$ & $16 \%$ & $98 \%$ & $2 \%$ & $\mathbf{0 . 0 0 0 5}$ \\
\hline N IPPV & $46 \%$ & $29 \%$ & $28 \%$ & $72 \%$ & $\mathbf{0 . 0 0 0 5}$ \\
\hline Intub & $1 \%$ & $90 \%$ & $2 \%$ & $98 \%$ & N/A \\
\hline Extub & $25 \%$ & $50 \%$ & $65 \%$ & $35 \%$ & $\mathbf{0 . 0 0 0 5}$ \\
\hline Adjust MV & $12 \%$ & $65 \%$ & $15 \%$ & $85 \%$ & $\mathbf{0 . 1}$ \\
\hline W eaning & $22 \%$ & $56 \%$ & $19 \%$ & $81 \%$ & $\mathbf{0 . 1}$ \\
\hline
\end{tabular}

Resp Tx = respiratory therapy

Position = positioning

Mob = mobilization

Intub = intubation

$\mathrm{N} / \mathrm{A}=$ not applicable

Extub $=$ extubation

N IPPV = non-invasive positive pressure ventilation

$M V=$ mechanical ventilation

care units but $4 \%$ of respondents from the government sector indicated no availability of a physiotherapy weekend service.

Comparing physiotherapy practice in the ICU in the government sector to practice in the private sector in South Africa didn't result in any statistically significant differences except with regards to the application of IPPB ( $p<0.05)$. One possible explanation could be that the prevalence of senior ICU physiotherapists was higher in the private sector and that these physiotherapists are more experienced in administering IPPB. There were no statistically significant differences between the European and South African surveys with regards to the practice of respiratory care, mobilization, positioning, intubation and adjustment of mechanical ventilation (see Table 4).

Physiotherapy interventions such as deep breathing exercises, postural drainage, manual therapy techniques, coughing, huffing, suctioning and mobilization are widely considered as the interventions of choice for patients that require physiotherapy treatment in the ICU setting (Berney and Denehey 2003; Hough 2001; Stiller 2000). Ciesla
(1996) stated that chest physiotherapy affected reduced incidence of pulmonary infection. Ntoumenopoulos et al (2002) reported that chest physiotherapy in ventilated patients was independently associated with a reduction in ventilatorassociated pneumonia. Berney and Denehy (2003) recently reported that physiotherapy treatment did not significantly alter mean oxygen uptake $\left(\mathrm{VO}_{2}\right)$, mean arterial pressure (MAP) or cardiac index (CI) in stable intubated and ventilated patients. Mobilization, exercise and the use of body positioning for ventilation-perfusion matching are physiotherapy interventions that are not normally considered as part of the treatment of critically ill patients in ICU (Wong 2000). The results from this pilot survey showed no statistically significant differences between the abovementioned physiotherapy interventions amongst respondents from the government and private sectors in South Africa and the respondents from the European survey. The results in Tables 3 and 4 show that these respondents used respiratory therapy, mobilization and positioning frequently in their daily practice.

This survey found no statistically significant difference regarding the 
involvement of physiotherapists in the European survey (22\%) and those in the South African survey (19\%) regarding the weaning process of a mechanically ventilated patient. The involvement of the respondents in this aspect of management of the critically ill patient in intensive care was small in both surveys. Ely et al (2001) stated that significant evidence existed to prove that allied health care professionals could implement respiratory care protocols that improved clinical outcomes for critically ill patients with respect to blood gas analysis or chest physiotherapy. On these grounds they recommended the inclusion of health care professionals (non-physician) in the development and utilization of weaning protocols in mechanically ventilated patients. Henneman et al (2001) investigated the effect of a collaborative weaning plan (CWP), in the form of weaning boards and flow sheets, on length of time of mechanical ventilation, length of ICU stay and cost. These authors found that the CWP led to a decreased length of stay in the medical ICU by 3.6 days and a decreased length of mechanical ventilation by 2.7 days. These studies indicated that a multidisciplinary approach to weaning was effective in improving patient outcomes in the ICU.

There was a statistically significant difference $(\mathrm{p}<0.05)$ in physiotherapy practice regarding extubation of the mechanically ventilated patient between the European (25\%) and the South African $(65 \%)$ surveys. In the United Kingdom a physiotherapist is only allowed to extubate a patient if he/she is able to re-intubate that patient in case of respiratory difficulties arising following extubation. Endotracheal intubation by physiotherapists in the United Kingdom is extended scope practice (CSP release document 1999).

This survey showed statistically significant differences $(p<0.05)$ between respondents in the South African survey's involvement (28\%) in noninvasive positive pressure ventilation (NIPPV) and the European respondents (46\%). Physiotherapists have been involved in the application of NIPPV, in the form of IPPB, since the 1950s. NIPPV in the form of CPAP and bi-level positive pres- sure has replaced IPPB in many hospitals worldwide. These devices are widely used in ICUs and high-dependency units and can be used on medical or surgical wards where adequate patient monitoring exists (Pryor and Prasad 2002). The physiotherapist may be involved with the application of NIPPV at the following levels of patient management: assessment of the patient, initiating NIPPV therapy, troubleshooting problems, planning a concurrent rehabilitation program, discharge planning and follow-up management (Pryor and Prasad 2002). Liesching et al (2003) and Sinuff et al (2003) reported that NIPPV could be beneficial for the following conditions: acute respiratory failure in patients with COPD exacerbations, acute pulmonary oedema, immunocompromised patients, post-thoracic and post-cardiac surgery. NIPPV could also be useful as a means of facilitating weaning from mechanical ventilation and preventing extubation failure. An explanation for the few South African physiotherapists being involved with NIPPV may be a lack of knowledge of the indications for NIPPV (as NIPPV may not be taught at all universities at an undergraduate level), lack of experience in implementing NIPPV and a lack of exposure to these devices in the hospitals were these physiotherapists work.

\section{CONCLUSION}

The response rate to this questionnaire was above expectation. The preliminary results from this pilot survey showed that the current scope of practice of the respondents working in ICU in South Africa didn't differ significantly between the government and the private sectors. It was also of interest that the current scope of practice of the respondents in the South African survey compared well with that of the respondents to the European survey. A limitation of this survey was the adaptation of the European questionnaire for the South African population without validation of the questionnaire. The questionnaire would have to be tested for reliability and validity through peer-review prior to use in future research on the scope of physiotherapy practice in ICU in South Africa. The results from this survey should therefore be viewed as preliminary from which only limited conclusions may be drawn. Further in-depth research into the scope of practice of South African physiotherapists in the ICU can provide valuable information to develop best clinical practice guidelines for the intensive care unit setting.

\section{REFERENCES}

Berney S, Denehy L 2003 The effect of physiotherapy treatment on oxygen consumption and haemodynamics in patients who are critically ill. Australian Journal of Physiotherapy 49: 99 $-105$

Ciesla N D 1996 Chest physical therapy for patients in the intensive care unit. Physical Therapy 76 (6): 609 - 622

Ely E W, Meade M O, Haponik E F, Kollef M H, Cook D J, Guyatt G H, Stoller J K 2001 Mechanical ventilator weaning protocols driven by non-physician health-care professionals. Chest 120: 454S - 463S

Henneman E, Dracup K, Ganz T, Molayeme O, Cooper C 2001 Effect of a collaborative weaning plan on patient outcome in the critical care setting. Critical Care Medicine 29 (2): $297-302$

Hough A 2001 Intensive care, monitoring and support. In: Physiotherapy in respiratory care: an evidence-based approach to respiratory and cardiac management, 3rd edition. pp 317 - 342. Nelson Thornes, Cheltenham

Liesching T, Kwok H, Hill NS 2003 Acute applications of noninvasive positive pressure ventilation. Chest 124: 699 - 713

Norrenberg M, Vincent J-L 2000 A profile of European intensive care unit physiotherapists. Intensive Care Medicine 26: 988 - 994

Ntoumenopoulos G, Presneill J J, McElholum M, Cade J F 2002 Chest physiotherapy for the prevention of ventilator-associated pneumonia. Intensive Care Medicine 28: 850 - 856

Physiotherapists working outside of the scope of physiotherapy practice. Release document PA21, September 1999, Chartered Society of Physiotherapy. http://www.csp.org.uk/library andinformation/publications

Pryor J A, Prasad S A 2002 Noninvasive ventilation In: Physiotherapy for respiratory and cardiac problems, 3rd edition. pp 323 - 345. Churchill Livingstone, Edinburgh

Sinuff T, Cook D J, Randall J, Allen C J 2003 Evaluation of a practice guideline for noninvasive positive pressure ventilation for acute respiratory failure. Chest 123: 2062 - 2073

Stiller K 2000 Physiotherapy in intensive care. Chest 118: 1801 - 1813

Wong W P 2000 Physical therapy for a patient in acute respiratory failure. Physical Therapy 80 (7): 662 - 670 